\title{
The flat-footed fly genus Seri Kessel \& Kessel (Diptera: Platypezidae)
}

\author{
JEFFREY M. CUMMING ${ }^{1} \&$ HEATHER J. CUMMING ${ }^{2}$ \\ ${ }^{\prime}$ Diptera Unit, Canadian National Collection of Insects, Invertebrate Biodiversity, Agriculture and Agri-Food Canada, K.W. Neatby \\ Building, 960 Carling Avenue, Ottawa, Ontario, K1A 0C6, CANADA. E-mail: Jeff.Cumming@AGR.GC.CA \\ ${ }^{2}$ Department of Natural Resource Sciences, McGill University, Macdonald Campus, Ste-Anne-de-Bellevue, QC, H9X 3V9, CANADA. \\ E-mail: heather.cumming2@mail.mcgill.ca
}

\begin{abstract}
Systematic information on the rarely collected Holarctic platypezid genus Seri Kessel \& Kessel is reviewed. Two species are included, S. obscuripennis (Oldenberg) from the Palaearctic Region and S. dymka (Kessel) from the Nearctic Region. The two species are diagnosed and the male of $S$. dymka is described for the first time. New records of $S$. dymka, previously recorded only from western North America, indicate that the species has a transcontinental distribution. The phylogenetic position and generic status of Seri is discussed.
\end{abstract}

Key words: Platypezidae, Platypezinae, Seri, Nearctic, Palaearctic

\section{Introduction}

The flat-footed fly genus Seri was erected by Kessel \& Kessel (1966) to include one rarely collected species, $S$. dymka, described earlier (in Clythia Meigen) by Kessel (1961) from western North America. Subsequently Chandler (1974) assigned the poorly known Palaearctic species Clythia (= Platypeza) obscuripennis Oldenberg to Seri based primarily on similarities in wing venation. Not much more has subsequently been published on the genus, although Chandler (2001) redescribed Seri based on S. obscuripennis and illustrated the male genitalia of that species (also illustrated in Chandler \& Shatalkin 1998).

Additional Nearctic specimens of Seri have now been studied, including the first known male of $S$. dymka. The purpose of this paper is to report on these specimens, describe the male of $S$. dymka, diagnose the included species and evaluate the status of the genus.

\section{Material and methods}

This study is based on material borrowed from or deposited in the following institutions and collections: California Academy of Sciences, San Francisco, CA, USA (CAS); Canadian National Collection of Insects, Ottawa, ON, Canada (CNC); Cornell University Insect Collection, Ithaca, NY, USA (CUIC); University of Guelph Insect Collection, Guelph, ON, Canada (DEBU); private collection of P.J. Chandler, Melksham, United Kingdom (PJC).

Morphological terminology for adult structures primarily follows McAlpine (1981) and Cumming and Wood (2009), except for the antenna and wing venation where the terms of Stuckenberg (1999) and Saigusa (2006) are used respectively. In the system outlined by Saigusa (2006), the dipteran wing vein $\mathrm{A}_{1}$ (as used in McAlpine 1981) is homologized with the mecopteran $\mathrm{CuP}$, and consequently $\mathrm{CuA}_{1}$ (of McAlpine) is termed $\mathrm{M}_{4}$, whereas $\mathrm{CuA}_{2}$ is $\mathrm{CuA}$, the anal cell is cell cua and the anal vein $\left(\mathrm{CuA}_{2}+\mathrm{A}_{1}\right)$ is $\mathrm{CuA}+\mathrm{CuP}$. The wing vein homologies as they relate to Platypezidae are shown in Figure 3.

Specimen photographs were taken using a Canon EOS 40D Digital SLR camera with an MP-E 65mm 1-5x macro lens mounted on a Kaiser RS1 copy stand. The male genitalic figure was prepared after macerating the ter- 
minalia in $85 \%$ lactic acid heated in a microwave oven, and tracing the genitalia in glycerine using a camera lucida attached to a compound microscope. The genitalic figure is oriented with the anatomically dorsal parts directed towards the top of the page and the anatomically ventral parts directed towards the bottom of the page, following the platypezid figures in Sinclair and Cumming (2006, figs. 355-357).

\section{Systematics}

\section{Genus Seri Kessel \& Kessel}

Seri Kessel \& Kessel, 1966: 98. Type species: Clythia dymka Kessel 1961 [Nearctic], by original designation.

Included species. Seri currently includes S. dymka (Kessel) and S. obscuripennis (Oldenberg).

Diagnosis. Seri is distinguished from other platypezid genera by the following combination of characters: relatively small flies 3-4 mm in length with body (Figs. 1,2) uniformly colored grey to black (male darker than female), without abdominal markings in female; head with parafacial bare, frons bearing long frontal setae in male (short setae in female); antenna with scape bare, pedicel with circle of preapical setae extended less than half length of postpedicel, postpedicel small and ovate, arista apical; thorax lacking acrostichal setae, with 3 notopleural setae; wing (Fig. 3) tinted brown in male and lighter greyish brown in female, covered with conspicuous microtrichia, crossvein $\mathrm{dm}-\mathrm{m}$ less than or subequal to its own length from wing margin, vein $\mathrm{M}_{1+2}$ branched with furcation nearer to crossvein $\mathrm{dm}-\mathrm{m}$ than to wing margin, cell cua about equal in length to apical section of anal vein $(\mathrm{CuA}+\mathrm{CuP})$; legs with mid tibia bearing one apical spur (lacking anteroventral spur); female hind tarsus with soles on anteroventral surface of tarsomeres 3 and 4, tarsomeres 1-3 broad, tarsomere 2 distinctly narrowed ventrally, tarsomere 3 longest; female abdomen with terminalia short, mostly retracted into segment 7 , sternite 7 with one or two pairs of strong erect setae; hypopygium of male (Fig. 4) with epandrium terminating in short blunt surstylus, hypandrium with paired elongate ventrally curved apical processes, phallapodeme keel-like, postgonite absent, phallus slender and elongate, sperm pump large and sclerotized with small ejaculatory apodeme.

Distribution. The genus is known from the Palaearctic (S. obscuripennis) and Nearctic (S. dymka) Regions.

Remarks. Adult specimens of Seri are most easily recognized by their tinted wings, which are conspicuously covered with microtrichia unlike many other platypezids that have clear glassier wings. The venation is also distinctive in that the furcation of $\mathrm{M}_{1+2}$ is nearer to crossvein $\mathrm{dm}-\mathrm{m}$ than to the wing margin, rather than the more common condition of having the furcation nearer to the wing margin.

According to Chandler (2001) Seri is most similar to the monotypic Palaearctic genus Bolopus Enderlein and is also similar to the small Holarctic/Oriental genus Polyporivora Kessel \& Maggioncalda. Unlike most other genera in the Platypezinae the mid tibia of these three genera ends in a single posteroventral spur, with the anteroventral spur being extremely reduced or absent. The antennal scape and parafacial are also bare in these three genera, and the male genitalia includes a large sclerotized sperm pump. Unlike Polyporivora however, Bolopus and Seri both have the wing covered with conspicuous microtrichia, the furcation of $M_{1+2}$ nearer to crossvein $\mathrm{dm}-\mathrm{m}$ than to the wing margin, and females that lack a pattern of abdominal markings. Bolopus differs from Seri in that crossvein $\mathrm{dm}-\mathrm{m}$ is more than $1.5 \mathrm{X}$ its length from the wing margin and the antenna has a circle of much longer preapical setae on the pedicel and a subdorsal rather than apical arista. In addition, the male genitalia of Bolopus have a larger pointed surstylus, a shorter hypandrial process and a short straighter phallus.

Kessel and Kessel (1966) and Chandler (1974) both commented, respectively, on how rarely S. dymka and $S$. obscuripennis appear to be collected, suggesting that each species may be overlooked by specialists because when resting they tend to resemble small muscid flies. However, with increased use of passive trapping techniques such as Malaise traps and pan traps during the last 40 years, many more specimens of Seri would be expected in collections if these flies were more common. 


\section{Seri dymka (Kessel)}

(Figs. 1-5)

Clythia dymka Kessel, 1961: 191 (female).

Platypeza dymka (Kessel): Kessel, 1965: 549.

Seri dymka (Kessel): Kessel \& Kessel, 1966: 99.
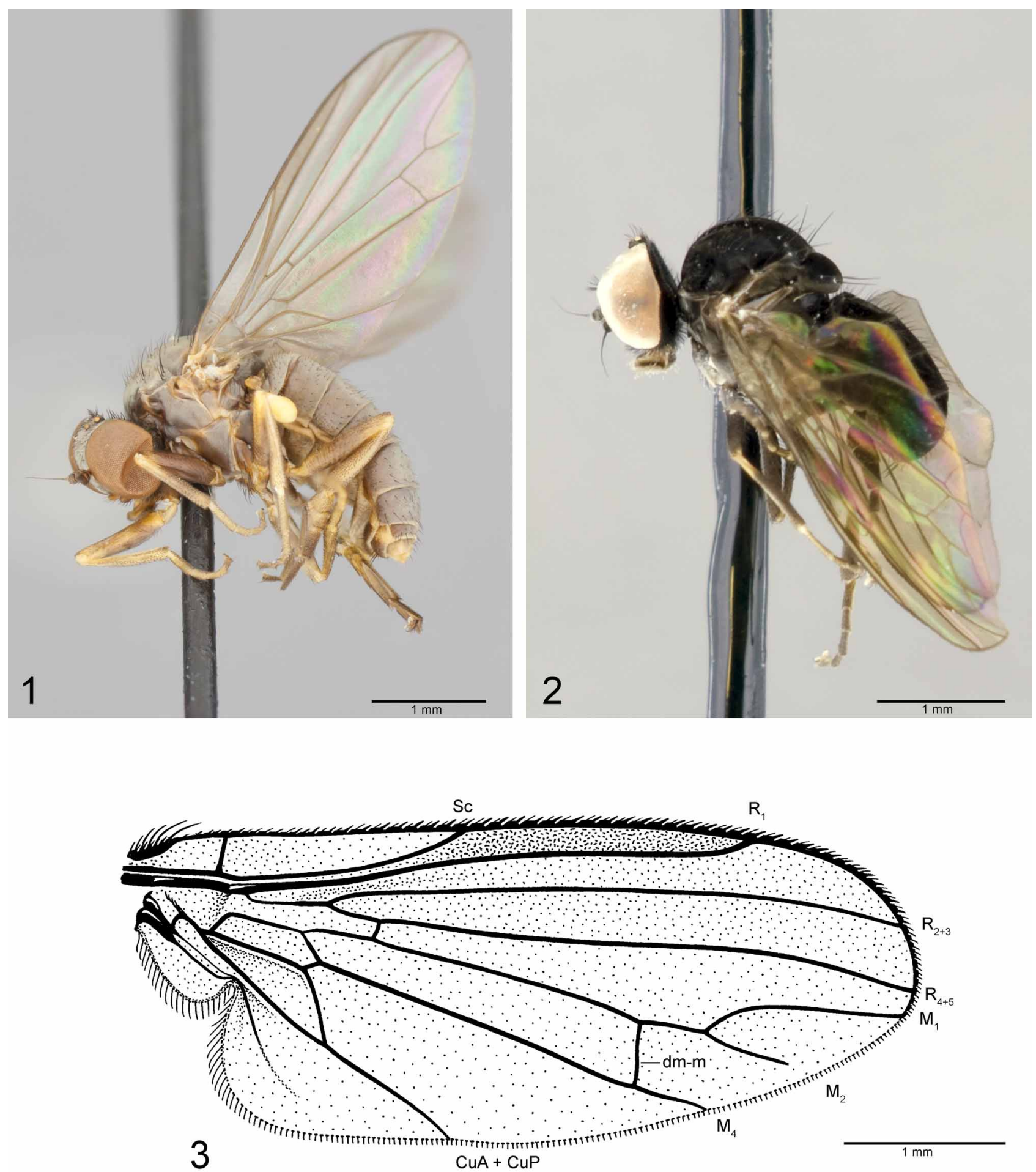

FIGURES 1-3. Habitus photographs and wing of Seri dymka Kessel. 1. female, lateral view. 2. male, lateral view. 3. wing of female (after Kessel 1987). Abbreviations: $\mathrm{CuA}+\mathrm{CuP}$ - anterior + posterior branch of cubital vein, dm-m—discal medial crossvein, $\mathrm{M}_{1}-1^{\text {st }}$ medial vein, $\mathrm{M}_{2}-2^{\text {nd }}$ medial vein, $\mathrm{M}_{4}-4^{\text {th }}$ medial vein, $\mathrm{R}_{1}-1^{\text {st }}$ radial vein, $\mathrm{R}_{2+3}-2^{\text {nd }}+3^{\text {rd }}$ radial vein, $\mathrm{R}_{4+5}-4^{\text {th }}$ $+5^{\text {th }}$ radial vein, $\mathrm{Sc}$ - subcostal vein. Scale in $\mathrm{mm}$. 
Diagnosis. Body color (Figs. 1, 2) grey in female with slight bluish hue in some specimens (without bluish hue in female $S$. obscuripennis), legs yellowish brown with tarsi more yellow (legs slightly darker in S. obscuripennis), male black with darker legs than female; wing of female (Fig. 3) with $\mathbf{M}_{2}$ longer than apical section of $\mathbf{M}_{1+2}$ (length of $\mathrm{M}_{2}$ slightly shorter in female $S$. obscuripennis); hind tarsomere 2 of female with one long anterior seta at apex; male genitalia with phallus projected only slightly beyond hypandrium (Fig. 4).

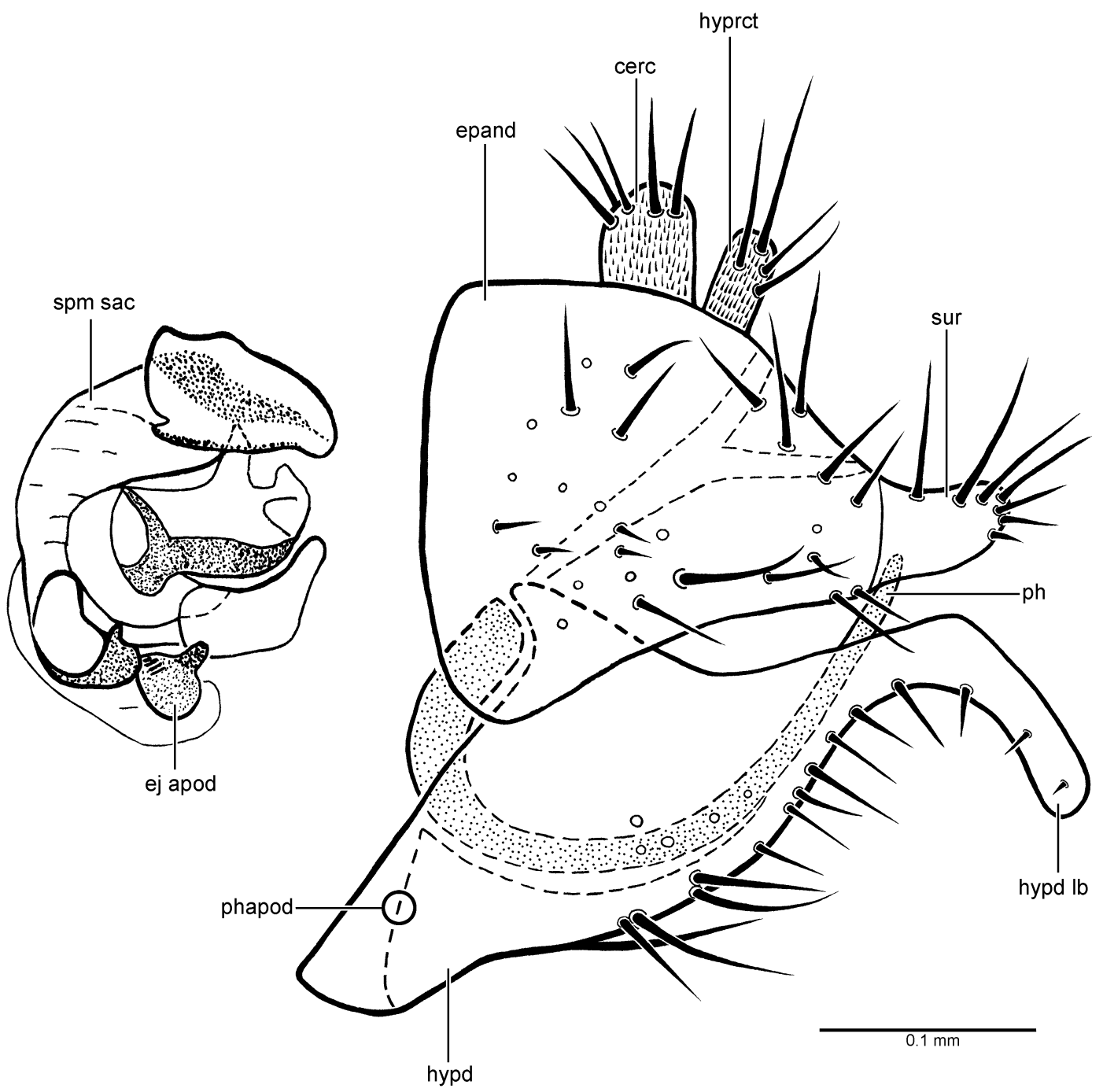

FIGURE 4. Male genitalia of Seri dymka (Kessel), left lateral view. Abbreviations: cerc—cercus, epand-epandrium, ej apod—ejaculatory apodeme, hypd—hypandrium, hypd lb—hypandrial lobe, hyprct—hypoproct, phapod—phallapodeme, ph—phallus, spm sac—sperm sac, sur—surstylus. Scale in mm.

Description (male). Body length $3.0 \mathrm{~mm}$. Body (Fig. 2) black except reddish brown eyes; antenna dark brown to black; scutum and scutellum with bluish reflections; legs dark brown with paler tibial bases and tarsi; wing tinted brown with cell sc darker. Head with setae of occiput extended on to and covering gena; frons with 7 pairs of frontal setae; ocellar tubercle with 5 pairs of ocellar setae; antenna with postpedicel bearing long apical and ventral microtrichia, lacking seta on dorsal margin. Thorax with 3 postpronotal setae, patch of posthumeral and presutural intra-alar setae, pluriserial row of postsutural intra-alar setae, row of uniserial dorsocentral setae becoming longer posteriorly, 1 supra-alar seta, 2 strong postalar setae, 2 scutellar setae on each side. Wing venation similar to female but with $\mathrm{M}_{2}$ shorter than apical section of $\mathrm{M}_{1+2}$. Hind tarsus expanded and laterally compressed, tarsomeres 1-3 broadest, tarsomeres 1 and 2 subequal in length, tarsomere 3 narrower and longer. Abdominal segments narrowed gradually towards apex with scattered setae on tergites (longest laterally); tergite 6 with row of erect setae on apical margin. Hypopygium (Fig. 4) dark brown to black with long setae on epandrium and hypandrium, surstylus with short stout setae on inner surface, hypandrium incised medioapically, phallus slender and projected slightly beyond 
hypandrium, sclerotized sperm pump large and multichambered with small ejaculatory apodeme, cercus and hypoproct fleshy and thinly sclerotized.

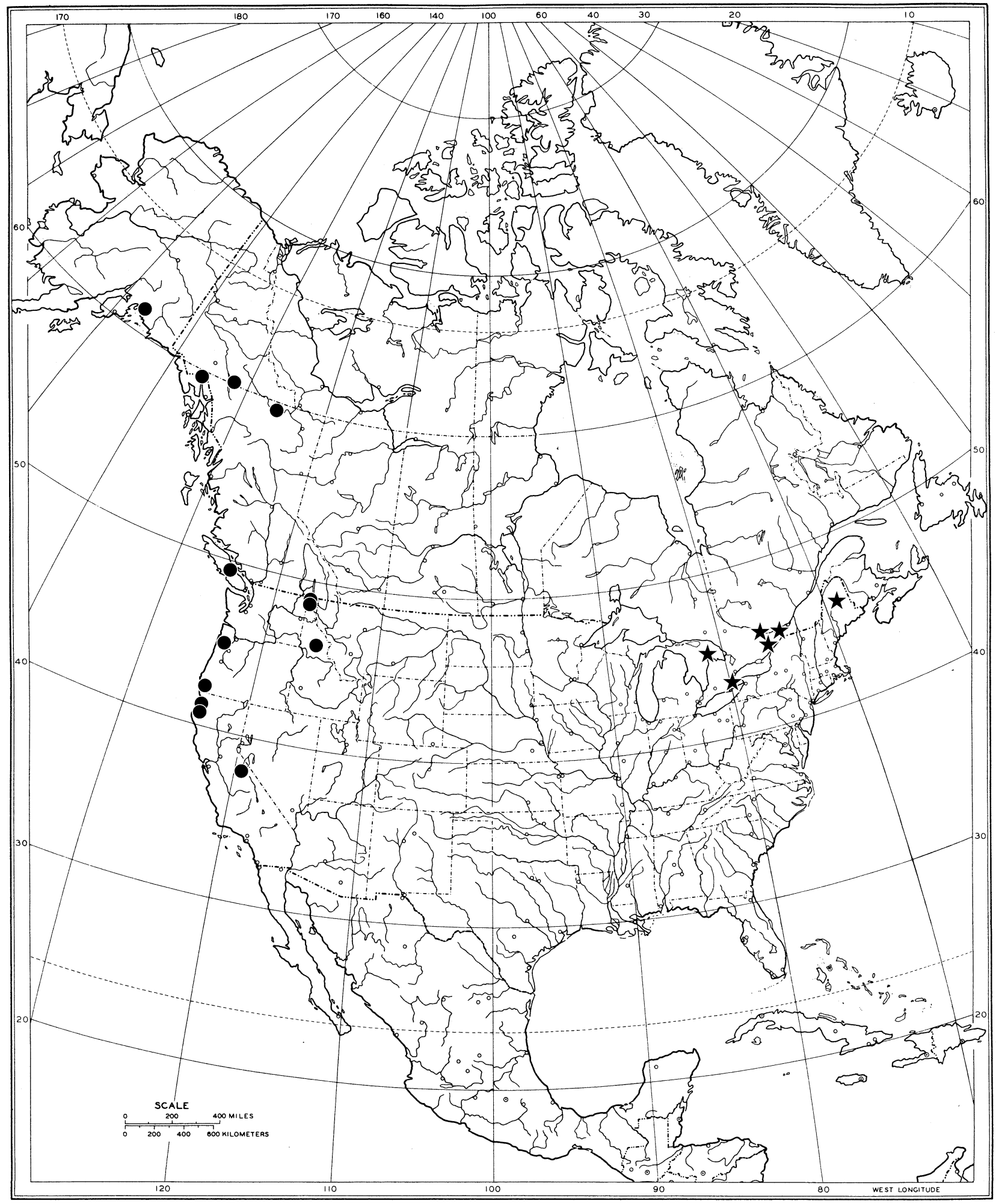

FIGURE 5. Known distribution of Seri dymka (Kessel). New records indicated with stars.

Known material. This species has been rarely, but widely, collected in North America (Fig. 5). Specimens deposited in CAS were not examined. Label information for CAS specimens was taken from Kessel and Kessel (1966) and all CAS specimens were collected by them. Specimens have been collected from the following locali- 
ties: CANADA: British Columbia: Stamp Falls, Vancouver Island, 13.X.1961, E.L. Kessel (2 $q$, CAS, CNC); Liard Hot Springs, Mile Post 496, Alaskan Highway, 2.IX.1957 (paratype $\odot$, CAS) and 8.VIII.1959 (1, , CAS). Ontario: Ottawa, swept over bare path in Acer wood, 18.IX.1989, J.R. Vockeroth (1 9 , CNC) and 1.X.1989, J.R. Vockeroth (1 9, CNC); Ottawa, lower Beachwood Cemetery Acer wood, aerial sweep, 23.IX.1993, J.R. Vockeroth (1 9 , CNC); Renfrew, Shaw Forest, ex. old maple forest, 27.VIII.1994, P.J. Chandler (1 + , PJC); Lanark Co., Mur-

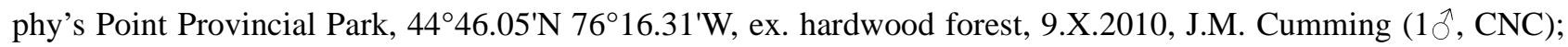

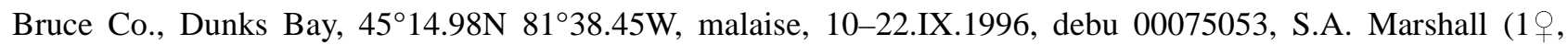
DEBU); Hamilton-Wentworth Co., Dundas Valley, Sherman Falls, ex. deciduous woodland, 12.IX.1994, P.J. Chandler (1 $q$, PJC). Yukon Territory: Alaska Highway and Morley River, 24.VII.1962 (1 $\circ$, CAS). USA: Alaska: 9 miles E of Valdez, 11-12.VII.1962, (4, CAS); Mosquito Lake, $27 \mathrm{mi} \mathrm{N}$ of Haines, 12.VIII.1959 (1 + , CAS) and 16.VII.1962 (1 + , CAS). California: Prairie Creek State Park, Humbolt Co., 4.XI.1960 (holotype $q$, paratype $q$, CAS); Yosemite Valley, Mariposa Co., 22.X.1960 (paratype +, CAS); Grizzly Creek Redwoods State Park, Humboldt Co., 21.X.1961 (1 + , CAS). Idaho: Reeder Bay, Bonner Co., 3.IX.1962 (1 + , CAS); Indian Creek State Park, $11 \mathrm{mi} \mathrm{N}$ of Coolin, Bonner Co., 3.IX.1962 (1q, CAS); 3 mi W of Lowell, Idaho Co., 30.VIII.1962 (1q, CAS). Maine: Mount Katahdin, Chimney Pd. trail, 25-3000', 2.VII.1958, H.C. Huckett (1 + , CUIC). Oregon: Van Duzer Corridor, Tillamook Co., 13.IV.1963 (1 , , CAS); Loeb State Park, Curry Co., 23.IV.1962 (1 , CAS).

Distribution. This species appears to be widely distributed in temperate forests of western North America and in northern hardwood forests of eastern North America (Fig. 5). Although it is possible that the eastern and western records represent disjunct populations of $S$. dymka, it seems more probable that this species has a transcontinental distribution and because of its rarity has yet to be collected in intervening forested areas.

Remarks. Chandler (1974) indicated that $\mathrm{M}_{2}$ is longer in the wing of $S$. dymka than in S. obscuripennis when compared with the length of the preceeding section of $\mathrm{M}_{1+2}$, but this feature is apparently only diagnostic for females of each species.

A comparison of male specimens from western and eastern North America is not currently possible, because males have not yet been collected in the west and only a single male is currently known from the east. Although future comparison with western males may reveal that the eastern Nearctic specimens of Seri represent a new species, no appreciable differences have been found between female specimens from eastern and western North America.

\section{Seri obscuripennis (Oldenberg)}

Clythia obscuripennis Oldenberg, 1916: 123 (male and female).

Platypeza obscuripennis (Oldenberg): Chandler, 1974: 22.

Seri obscuripennis (Oldenberg): Chandler, 1974: 22.

Diagnosis. Body color grey in female without bluish hue, legs greyish brown with tarsi more yellowish brown, male black with darker legs than female; wing of female with $\mathrm{M}_{2}$ equal to apical section of $\mathrm{M}_{1+2}$ (see Chandler 1974, fig. 22); hind tarsomere 2 of female with two long anterior setae at apex (see Chandler 2001, fig. 277); male genitalia with phallus projected well beyond hypandrium (see Chandler \& Shatalkin 1998, fig. 29; Chandler 2001, fig. 278).

Larva and puparium described by Chandler (2001) and Rotheray et al. (2004): larva cylindrical, slightly dorsoventrally flattened, lateral and dorsal processes of body segments inconspicuous and hair-like, anal segment with small pair of caudal wart-like protuberances; puparium with dehiscence lines of operculum along lateral margins of segments $2-4$ and posteriorly along basal two thirds of tergite 5 .

Distribution. Although rarely collected, this species is widespread in the Palaearctic Region having been recorded from Europe (Britain, Norway, Sweden, Finland, Netherlands, Poland, Czech Republic, Switzerland, Austria, Hungary, Romania, Central Russia) and the Russian Far East (Amur Region) (Chandler 1991, 2001). Shatalkin (1985) indicated that S. obscuripennis was more commonly collected in the Amur Region than in Central Russia. Ševčík (2001) and Webb (2004) were also able to obtain series of adult specimens by rearing larvae from Polyporus fungi in the Czech Republic and Britain, respectively.

Remarks. Despite lack of males, Chandler (1974) considered it best to maintain S. obscuripennis and S. dymka as separate species, because closely related Palaearctic and Nearctic platypezid taxa have generally been found to be specifically distinct. Comparison of the different phallus lengths in both species now supports Chandler's deci- 
sion. Chandler (2001, fig. 277) also illustrated the female hind tarsus of S. obscuripennis with two long anterior setae at the apex of tarsomere 2, whereas females of $S$. dymka consistently have only one long anterior seta. This may be an additional diagnostic feature that distinguishes females of the two species.

Vaňhara (1986) recorded a single adult of $S$. obscuripennis from a light trap set in a hardwood forest in the Czech Republic. Ševčík (2001) and Webb (2004) reared larvae S. obscuripennis from tough textured Polyporus fungi species, namely P. durus (= P. badius) and P. varius. The host association with the softer textured Polyporus squamosus fungus suggested by Chandler (2001) appears to have been incorrect (Webb 2004).

\section{Discussion}

Seri appears related to the Holarctic/Oriental genus Polyporivora and the Palaearctic genus Bolopus on the basis of a bare scape and parafacial, extreme reduction or loss of the anteroventral mid tibial spur, and a similar larva (not known for $S$. dymka) that is cylindrical in form with reduced (except for a median anal pair) marginal processes (Chandler 2001). In addition, all three genera share an enlarged sclerotized sperm pump of the male genitalia. As stated by Chandler (2001) the lineage appears adapted to feeding on polypore fungi, which is probably facilitated by the smooth cylindrical shape of the larva (Rotheray et al. 2004). The three genera may also be related to the Chilean species Platypeza brunnescens Collin. According to Chandler $(2001,2010)$ this species, which resembles Seri in many respects (e.g. wing venation), retains two mid tibial spurs and probably represents a new undescribed genus near the base of this lineage.

Polyporivora is distinct from both Seri and Bolopus in terms of several apomorphic features including in the venation, male genitalia, female terminalia, and on the larva, whereas Seri and Bolopus appear to share the plesiomorphic condition in these features (Chandler 2001). Therefore although appearing similar, Seri and Bolopus together probably do not form a monophyletic group. As a result synonymyzing Seri with Bolopus does not seem feasible based on current evidence. In addition, Bolopus and Seri are quite distinct in terms of their antennae, male frontal setae and additional features of the male genitalia (i.e. shape of the surstylus and phallus, as well as length of the hypandrial process).

Additional sampling for Nearctic specimens of Seri is needed to obtain males from western localities. Comparison of eastern and western male specimens will assist in determining whether eastern and western populations represent distinct species. Increased sampling effort should also provide specimens that are appropriate for future studies employing molecular techniques. Unfortunately only one of the specimens reported on in this paper (i.e. the unique male of $S$. dymka) was collected in the last 15 years. Sequence data extracted from more recently collected specimens of Seri should also help determine species status in these rarely collected flies.

\section{Acknowledgements}

We thank Steve Marshall (DEBU) and Rick Hoebeke (CUIC) for the loan of specimens. Alan Fleming (CNC) kindly took the photographs of Seri dymka. Scott Brooks (CNC) prepared the distribution map and labelled the plates. He and Brad Sinclair (CNC), as well as Terry Wheeler (Department of Natural Resource Sciences, McGill University) made helpful comments on the manuscript. Peter Chandler (Melksham, United Kingdom) is acknowledged for providing valuable information on Seri. The second author was supported by a Natural Sciences and Engineering Research Council of Canada Discovery Grant to Terry Wheeler.

\section{References}

Chandler, P.J. (1974) Additions and corrections to the British list of Platypezidae (Diptera), incorporating a revision of the Palaearctic species of Callomyia Meigen. Proceedings and Transactions of the British Entomological Society, 7, 1-32.

Chandler, P.J. (1991) Platypezidae. In: Soos, A. \& Papp, L. (Eds.), Catalogue of Palaearctic Diptera, Volume 7, Dolichopodidae-Platypezidae. Elsevier Science Publishing, pp. 205-217.

Chandler, P.J. (2001) The flat-footed flies (Diptera: Opetiidae and Platypezidae) of Europe. Fauna Entomologica Scandinavica, $36,1-276$. 
Chandler, P.J. (2010) Platypezidae (flat-footed flies). In: Brown, B.V., Borkent, A., Cumming, J.M., Wood, D.M., Woodley, N.E. \& Zumbado, M.A. (Eds.), Manual of Central American Diptera, Volume 2, NRC Research Press, Ottawa, Ontario, Canada, pp. 715-719.

Chandler, P.J. \& Shatalkin, A.I. (1998) Family Platypezidae. In: Papp, L. \& Darvas, B. (Eds.), Contributions to a Manual of Palaearctic Diptera, Volume 3, Higher Brachycera. Science Herald, Budapest, pp. 27-49.

Cumming, J.M., \& Wood, D.M. (2009) Adult morphology and terminology. In: Brown, B.V., Borkent, A., Cumming, J.M., Wood, D.M., Woodley, N.E. \& Zumbado, M.A. (Eds.), Manual of Central American Diptera, Volume 1, NRC Research Press, Ottawa, Ontario, Canada, pp. 9-50.

Kessel, E.L. (1961) New species of flat-footed flies from North America (Diptera: Platypezidae). The Wasmann Journal of Biology, 19, 191-227.

Kessel, E.L. (1965) Family Platypezidae. In: Stone, A., Sabrosky, C.W., Wirth, W.W., Foote, R.H. \& Coulson, J.R. (Eds.), A catalog of the Diptera of America north of Mexico. United States Department of Agriculture, Agricultural Research Service, Agriculture Handbook, 276, pp. 546-550.

Kessel, E.L. (1987) Platypezidae. In: McAlpine, J.F., Peterson, B.V., Shewell, G.E., Teskey, H.J., Vockeroth, J.R. \& Wood, D.M. (Coords.), Manual of Nearctic Diptera, Volume 2. Agriculture Canada Monograph, 28, pp. 681-688.

Kessel, E.L. \& Kessel, B.B. (1966) Seri, a new genus of Platypezidae from North America (Diptera). The Wasmann Journal of Biology, 24, 97-100.

McAlpine, J.F. (1981) Morphology and terminology - Adults. In: McAlpine, J.F., Peterson, B.V., Shewell, G.E., Teskey, H.J., Vockeroth, J.R. \& Wood. D.M. (Coords.), Manual of Nearctic Diptera, Volume 1. Agriculture Canada Monograph No. 27, pp. 9-63.

Oldenberg, L. (1916) Neue europaïsche und südamerikanische Clythiiden (= Platypeziden; Dipt.). Archiv für Naturgeschichte, Abteilung A, 82 (1), 120-136.

Rotheray, G.E., Chandler, P.J. \& Gilbert, F. (2004) Final stage larvae and puparia of Platypezidae (Diptera). Insect Systematics and Evolution, 35, 79-106.

Saigusa, T. (2006) Homology of wing venation of Diptera. Unpublished handout distributed at the $6^{\text {th }}$ International Congress of Dipterology, Fukuoka, Japan.

Ševčík, J. (2001) Diptera (excluding Mycetophilidae s.str.) associated with fungi in Czech and Slovak Republics: a survey of rearing records from 1998-2000. Acta Universitatis Carolinae Biologica, 45, 157-168.

Shatalkin, A.I. (1985) [A revision of the flat-footed flies (Diptera, Platypezidae) of USSR]. Archives of Zoological Museum Moscow State University, 23, 69-136 [in Russian].

Sinclair, B.J., \& Cumming, J.M. (2006) The morphology, higher-level phylogeny and classification of the Empidoidea (Diptera). Zootaxa, 1180, 1-172.

Stuckenberg, B.R. (1999) Antennal evolution in the Brachycera (Diptera), with a reassessment of terminology relating to the flagellum. Studia dipterologica, 6, 33-48.

Vaňhara, J. (1986) The flat-footed flies (Opetiidae and Platypezidae, Diptera) in a lowland forest. Dipterologica Bohemoslovaca, 4, 79-84.

Webb, J.A. (2004) Rearing records of Seri obscuripennis (Oldenberg) (Diptera, Platypezidae) from Oxforshire. Dipterist Digest (Second Series), 11, 143. 